\title{
Assessment of functional impairment after knee anterior cruciate ligament reconstruction using cardiorespiratory parameters: a cross-sectional study
}

Marília Santos Andrade ${ }^{1 *}$, Claudio Andre Barbosa de Lira², Rodrigo Luiz Vancini ${ }^{3}$, Fernanda Patti Nakamoto ${ }^{1}$, Moisés Cohen ${ }^{4}$ and Antonio Carlos da Silva ${ }^{1}$

\begin{abstract}
Background: A dynamic sub-maximum exercise with the same absolute intensity, performed with different muscle groups, may present exacerbated cardiorespiratory responses. Therefore, cardiorespiratory responses to unilateral exercise may identify bilateral differences. The purpose of this study was to verify whether the cardiorespiratory responses to lower limb exercise display counter-lateral differences, and if they could be used to assist athletes and health professionals involved in rehabilitation.

Methods: Nine individuals participated in this cross-sectional study. They had been treated in a private rehabilitation clinic and submitted to intra-articular reconstruction of the anterior cruciate ligament. The cycling exercise with the same sub-maximal intensity and with one lower limb was used to gather data. Cardiorespiratory responses to exercise were compared between exercises performed with the involved and uninvolved limb after five minutes of exercise.

Results: Cardiorespiratory responses to exercise performed with the involved limb presented higher values after five minutes of cycling: oxygen uptake $(+7 \%)$, carbon dioxide production $(+10 \%)$, minute ventilation $(+20 \%)$, breathing frequency $(+19 \%)$, ventilatory equivalent for oxygen $(+14 \%)$, end-tidal pressure of $\mathrm{O}_{2}$ oxygen $(+4 \%)$, end-tidal pressure of $\mathrm{O}_{2}$ carbon dioxide $(-9 \%)$ and heart rate $(+9 \%)$.

Conclusions: The exacerbated responses, including increase of the ventilatory equivalent and decrease of end-tidal pressure of carbon dioxide, indicate that this exercise protocol may be useful in the characterization of the functional deficit of the surgical limb during rehabilitation.
\end{abstract}

Keywords: Knee injury rehabilitation, Physiological responses, Heart rate, Oxygen uptake

\section{Background}

Knee anterior cruciate ligament (ACL) reconstruction is a common surgical procedure. In order to return to the original level of function as quickly and safely as possible, the patient must follow a rehabilitation protocol [1]. There is no agreement in relation to a optimal rehabilitation program following ACL reconstruction.

Recovery of the quadriceps muscle strength, power and endurance is among the main goals of the ACL

\footnotetext{
* Correspondence: marilia1707@gmail.com

'Departamento de Fisiologia, Universidade Federal de São Paulo, São Paulo, Brazil

Full list of author information is available at the end of the article
}

rehabilitation programs because it is closely related to knee function [2]. Traditionally, muscle strength can be measured by manual muscle testing but this testing value is limited in detecting changes in strength [3-5]. Isokinetic dynamometers are also appropriate to detect changes in strength [6-8]. However, this equipment is expensive and its use during the initial months after surgery puts the patients at risk of exerting high levels of graft tension [9-11]. Thus, a safe method to assess exercise efficiency without increasing ACL graft load is required in the immediate post-operative phase.

In this context, a dynamic sub-maximum exercise with the same absolute intensity, performed with

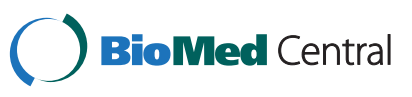


different muscle groups, may present exacerbated metabolic and cardiorespiratory responses. When the muscle group exercised presents lower functional capacity, the exercise will consequently be performed under higher relative physiological demand. Many authors reached that conclusion by contrasting arm cranking and cycling [12-14]; by comparing one to two legs cycling [15]; or when analyzing normal lower limb and lower limb with muscle atrophy [16]. However, these studies compared very different muscle mass, and we do not yet know if these cardiopulmonary-exacerbated responses can be observed when the exercises are undertaken with similar muscle mass, for instance, in a clinical post-surgical situation.

Therefore, the purpose of this study was to determine if there are differences in cardiorespiratory responses to exercise performed after unilateral ACL reconstruction, when the lower limb presents significant functional deficiency, at a constant submaximal intensity. We hypothesized that there are differences in cardiorespiratory responses to exercise performed with the involved limb when compared to the non-involved limb. This knowledge may contribute to the development of an objective physiological accessory criterion which would evaluate the existence of differences between limbs regarding functional status and muscle mass after surgery.

\section{Methods \\ Participants}

Nine participants (two women and seven men) volunteered to participate in this study. All participants trained at least for three days per week (3.5 \pm 0.6 days per week), about 60 minutes per day, for at least one year before ACL lesion and they were sequentially invited to participate in the study, as they started the rehabilitation program, in a private orthopaedic clinic. The characteristics of the participants (mean \pm standard deviation - SD) were as follows: age $=32.0 \pm 1.4$ years, body mass $=71.8 \pm 10.8 \mathrm{~kg}$ and height $=172.5 \pm 7.5 \mathrm{~cm}$. The participants had ACL disruption and were submitted to intra-articular reconstruction of the ACL with patellar tendon graft by the same medical surgical team and participated in an intensive rehabilitation program in a private clinic. Briefly, the participants trained three times a week throughout the rehabilitation period and both limbs were treated. The assessment took place about two months after the surgical procedure $(8.0 \pm$ 1.3 weeks). The patients were informed about the purpose of the research and were asked to give their written consent to participate in a protocol approved by University Ethical Committee of Federal University of Sao Paulo. All procedures were in accordance with recommendations from the Declaration of Helsinki.

\section{Procedure}

Participants were given a standardized set of instructions before performing the tests. The one-legged cycling exercise was performed on a bicycle (The Bike, Cybex, USA), with the patient in an upright position. On the first day, athletes started the pre-tests with the noninvolved limb, with the aim of deciding the test absolute workload. Pre-tests consisted of some three minute exercise trials, in order to find the workload in which the heart rate (HR) was kept at $70 \%$ of the predicted maximum value (by 220 minus age), monitored using an HR monitor (Polar Electronics, Vantage, Finland). The same absolute workload was used in both limbs. On the second day, the exercise began with the involved limb. For rest measurements, the patient did not cycle for the first three minutes. This period was followed by cycling for five minutes with one limb. Afterwards, the patient recovered until the rest HR was reached. The same exercise protocol was repeated using the non-involved limb on the same day. During the test, respiratory gas samples were analyzed breath-to-breath using a portable metabolic system ( $\mathrm{K}_{4} \mathrm{~b}^{2}$, Cosmed, Italy) and each consecutive 20 -second reading was averaged in order to smooth data. Before each test, the gas analyzers were calibrated according to the manufacturer's recommendations. The variables measured were: oxygen uptake $\left(\dot{V} \mathrm{O}_{2}\right)$, carbon dioxide production $\left(\dot{V} C \mathrm{O}_{2}\right)$, minute ventilation $\left(\dot{V}_{E}\right)$, breathing frequency $(f)$, tidal volume $\left(\mathrm{V}_{\mathrm{T}}\right)$, ventilatory equivalent for $\mathrm{O}_{2}\left(\dot{V}_{E} \mathrm{O}_{2}\right)$, ventilatory equivalent for $\mathrm{CO}_{2}\left(\dot{V} E C \mathrm{O}_{2}\right)$, endtidal pressure of $\mathrm{O}_{2}\left(\mathrm{P}_{\mathrm{ETO} 2}\right)$, end-tidal pressure of $\mathrm{CO}_{2}$ $\left(\mathrm{P}_{\mathrm{ETCO} 2}\right)$, and HR.

\section{Statistical analysis}

Components used for sample size calculation were type I $(\alpha)$ or type II $(\beta)$ errors. Type I was set as $5 \%$ and type II as $20 \%$. For sample size calculation we used mean and $\mathrm{SD}$ values for HR and VE responses to exercise, extracted from similar previous studies, as it was recommended by Noordzij et al. [17]. The used values for VE calculation were: mean $1=98.13 \mathrm{~L} / \mathrm{min}$ and mean $2=79.18 \mathrm{~L} / \mathrm{mim}$ and $\mathrm{SD}=14.0 \mathrm{~L} / \mathrm{min}$ [18]. The used values for $\mathrm{HR}$ calculation were mean $1=213.8 \mathrm{bpm}$ and mean $2=194.8 \mathrm{bpm}$ and $\mathrm{SD}=7.4 \mathrm{bpm}[18]$. The target number was 9 participants.

The last 20 seconds of exercise were used to determine data obtained from cardiorespiratory responses to exercise assessment. All variables presented normal distributions according to Kolmogorov-Smirnov tests. A paired Student's $t$-test was used to compare variables obtained from the involved and non-involved limbs, and the level of significance was set at $\mathrm{p}<0.05$. In addition, we calculated the effect-size correlation values, using the means and standard deviations data. The results were expressed as mean \pm standard deviation. 


\section{Results}

After five minutes of exercise under a constant submaximal intensity, significant increases were found in $\dot{V} \mathrm{O}_{2}$ $(+7 \%) \dot{V} C_{2}(+10 \%) \dot{V}_{E}(+20 \%) f(+19 \%), \dot{V}_{E} O_{2}(+14 \%)$, $\mathrm{P}_{\mathrm{ETO} 2}(+4 \%), \mathrm{P}_{\mathrm{ETCO} 2}(-9 \%)$ and $\mathrm{HR}(+9 \%)$ values when the exercise performed with the involved limb was compared to that performed with the non-involved limb (Table 1). No significant differences were found concerning $\dot{V}_{E} C_{2}$ values after five minutes of activity $(\mathrm{p}=0.08)$.

\section{Discussion}

There are a lot of studies that aim to assess the ability of a patient to progress through the end stages of rehabilitation after ACL reconstruction [19-22]. However, it is very difficult to obtain safe and objective markers during the initial phases. In particular, the characterization of the functional level of the quadriceps is essential in order to determine an appropriate, low-risk increase in intensity of the rehabilitation load, considering the significant hypotrophy that this muscle presents after the surgical procedure, as well as its role in the stability of the knee joint [23]. Dynamic functional testing, for example the horizontal hop test, reproduces the functional movement, although its accuracy is somewhat questionable. Often, compensatory activities, such as swinging the arms, forward movement of the nonsupporting lower limb or extending the trunk, mask deficits in the involved lower limb [24]. Furthermore, hop tests have been used only 4 or 6 months after surgery [20-22].

Other measurements can provide information about the deficiency in the involved lower limb. Thigh circumference is frequently used in the evaluation of muscle trophic

\begin{tabular}{|c|c|c|c|c|}
\hline Variable & Uninvolved limb & Involved limb & $\mathbf{P}$ & Effect size \\
\hline$\dot{\mathrm{V}} \mathrm{O}_{2}(\mathrm{~mL} / \mathrm{min})$ & $1680.4 \pm 335.9$ & $1802.7 \pm 357.4^{*}$ & 0.02 & -0.17 \\
\hline$\dot{\mathrm{V}} \mathrm{CO}_{2}(\mathrm{~mL} / \mathrm{min})$ & $1679.1 \pm 259.4$ & $1865.9 \pm 314.8^{*}$ & 0.005 & -0.30 \\
\hline$\dot{V} E(L / \min )$ & $54.1 \pm 7.8$ & $67.8 \pm 15.4^{*}$ & 0.02 & -0.49 \\
\hline $\mathrm{Vt}(\mathrm{L})$ & $2.1 \pm 0.4$ & $2.2 \pm 0.4$ & 0.47 & - \\
\hline$f(\mathrm{bpm})$ & $26.4 \pm 6.6$ & $32.2 \pm 9.6^{*}$ & 0.048 & -0.33 \\
\hline$\dot{V} E O_{2}$ & $31.7 \pm 7.4$ & $36.7 \pm 8.8^{*}$ & 0.047 & -0.30 \\
\hline$\dot{\mathrm{V}} \mathrm{ECO}_{2}$ & $31.1 \pm 6.2$ & $34.9 \pm 6.1$ & 0.08 & - \\
\hline $\mathrm{PetO}_{2}(\mathrm{mmHg})$ & $99.6 \pm 6.4$ & $103.8 \pm 5.8^{*}$ & 0.03 & -0.32 \\
\hline $\mathrm{PetCO}_{2}(\mathrm{mmHg})$ & $36.3 \pm 5.7$ & $33.0 \pm 4.9^{*}$ & 0.04 & 0.30 \\
\hline HR (beats.min ${ }^{-1}$ ) & $149 \pm 16$ & $162 \pm 21^{*}$ & 0.005 & -0.33 \\
\hline
\end{tabular}

Data are expressed as mean \pm standard deviation; *Statistically significant difference in relation to non-involved $\operatorname{limb}(\mathrm{p}<0.05) . \dot{V} \mathrm{O}_{2}$ : oxygen uptake, $\dot{V} \mathrm{CO}_{2}$ : carbon dioxide production, $\dot{V}_{E}$ : minute ventilation, $f$ : breathing frequency, $V_{\mathrm{T}}$ : tidal volume, $\dot{V}_{E} \mathrm{O}_{2}$ : ventilatory equivalent for $\mathrm{O}_{2}, \dot{V} E \mathrm{VO}_{2}$ : ventilatory equivalent for $\mathrm{CO}_{2}, \mathrm{P}_{\mathrm{ETO} 2}$ : end-tidal pressure of $\mathrm{O}_{2}, \mathrm{P}_{\mathrm{ETCO} 2}$ : end-tidal pressure of $\mathrm{CO}_{2}$ and HR: heart rate. conditions, although it underestimates the existing hypotrophy [25]. The Lysholm questionnaire can also be used to clinically evaluate knee conditions according to the patient's perception [26].

Thus, in the present study, considering that the activity on the cycle ergometer is usually performed in the early stages of the rehabilitation procedure, we investigated whether the cardiorespiratory responses to exercise during dynamic constant submaximal intensity exercise in individuals that have undergone ACL reconstruction would be different between involved and non-involved limbs, two months after ACL reconstruction surgery. We found that cardiorespiratory responses obtained from exercise performed with the involved limb were exacerbated when compared with data from the exercise performed with the non-involved limb, at the same absolute workload.

In the current study, after five minutes of exercise in the cycloergometer, the $\dot{V} \mathrm{O}_{2}, \dot{V} C O_{2}, \mathrm{HR}$, and $\dot{V}_{E}$ presented higher values for the exercise with the involved limb. Such results probably reflect lower movement economy during the exercise performed with the involved limb as a consequence of poor oxidative status and lower involved muscle mass. The ventilatory effect was mainly determined by the breath rate, since the tidal volume did not vary significantly. The higher values of $\mathrm{P}_{\mathrm{ET}} \mathrm{O}_{2}$ and $\dot{V} E \mathrm{O}_{2}$ indicate that the ventilatory response per litre of $\mathrm{O}_{2}$ is increased in the exercise performed by the involved limb, representing a higher relative workload, although both limbs had worked under the same absolute workload. Some researchers also compared the cardiorespiratory responses to exercises performed with muscle groups of different functional capacities [13,27]. Likewise, the authors observed that in the same absolute workload there was an increase in HR and in $\dot{V} E O_{2}$ values during exercises that involved muscle groups submitted to a higher relative work intensity. Such effect is similar to that described by Wasserman et al. [28] for the incremental effort test and may indicate a major contribution of the anaerobic metabolism for the exercise with the involved limb. This analysis endorses the evidence that the same absolute workloads, applied to both limbs, represent a higher relative intensity for the involved limb, probably reflecting a functional deficit in the recovering limb.

In practical terms, as mentioned above, variables such as HR and $f$ are exacerbated during the exercise performed with the involved limb, therefore monitoring these variables offers opportunities to directly evaluate the physiological profile of discipline-specific performance in an easy and inexpensive way. This suggests that health providers can use $\mathrm{HR}$ and $f$ to form conclusions about the functional status of the involved limb.

Altogether, these findings corroborate previous studies regarding muscle strength deficiency after ACL surgery. 
Andrade et al. [25] showed that 4 months after ACL surgery, muscle peak torque deficiency in the quadriceps muscle was on average $46.7 \%$ and Strauss et al. [29] found $21.4 \%$. Laffargue et al. [30] tested patients 6 months after surgery and found a quadriceps muscle deficit of $28.3 \%$. However, despite the use of isokinetic muscle strength testing by clinicians and physical therapists to assess possible contra-lateral deficiencies and muscular balance, muscle strength testing conducted by isokinetic dynamometer may compromise the articular stability of the knee when applied during the initial months after surgery. Thus, the methodology proposed by this study could be an interesting alternative to evaluate and address the functional capacity of the muscle after ACL surgery. Furthermore, there are currently many studies investigating molecular composition (gene or protein levels) of the structures used for ACL repair in order to identify the best structure for a quicker rehabilitation [31]. Strategies to enhance the ACL healing process through overexpression of fibroblast growth factor (a powerful stimulator of fibroblast proliferation and type I/III collagen production) via direct recombinant adeno-associated virus vector-mediated gene transfer has also been investigated [32]. The results have a potential value for the development of novel and effective treatments for ligament reconstruction. Therefore, alternative measurements of functional evaluation after ACL surgery may also be useful to evaluate how these new interventions to accelerate ACL healing are effective in improving rehabilitation after ACL surgery.

\section{Limitations}

In this study, we showed that after 2 months of a rehabilitation program following $\mathrm{ACL}$ reconstruction there are significant differences in cardiorespiratory responses to exercise when performed by the involved limb. However, we did not evaluate the how these bilateral cardiorespiratory differences changes with the muscular recovery during the rehabilitation phase until the patients are able to return to their normal sports activities. Another limitation may be the composition of the sample, which was taken by man and women with different ages. Another ligament injuries, besides ACL and the level of physical activity performed by the volunteers before the sugery also may be limitations of this study.

\section{Conclusions}

Considering that both the $\dot{V} E$ and HR responses were exacerbated during the exercise performed with the involved limb, when a dynamic exercise, of constant workload and same absolute intensity ( $70 \%$ of the maximum HR during the exercise with the non-involved) was performed, the responses from the two variables could be measured to show incomplete muscle recovery of the involved limb.

\section{Clinical implications}

Two months after unilateral ACL reconstruction there are differences in cardiorespiratory adjustments, such as HR and $f$, to dynamic exercise performed by uninvolved or involved lower limbs. These findings can contribute to the development of an easy and inexpensive rehabilitation monitoring protocol, with physiological bases, which may show the evolution of the patient over the initial months of rehabilitation after ACL reconstruction, taking the non-involved limb as reference.

\section{Abbreviations}

ACL: Anterior cruciate ligament; $f:$ Breathing frequency; HR: Heart rate; $P_{\text {ETCO2: }}$ : End-tidal pressure of $\mathrm{CO}_{2} ; P_{\text {ETO2: }}$ : End-tidal pressure of $\mathrm{O}_{2} ; \dot{V}_{E}$ : Minute ventilation; $\dot{V} E \mathrm{CO}_{2}$ : Ventilatory equivalent for $\mathrm{CO}_{2} ; \dot{V}_{E} \mathrm{O}_{2}$ : Ventilatory equivalent for $\mathrm{O}_{2} ; \mathrm{VO}_{2}$ : Oxygen uptake; $\mathrm{V} \mathrm{CO}_{2}$ : Carbon dioxide production; $V_{T}$ : Tidal volume.

\section{Competing interests}

No commercial party having a direct financial interest in the results of the research supporting this article has granted or will grant any benefits to the authors or any organization with which the authors are associated.

\section{Authors' contributions}

MSA: study concept and design; data acquisition, analysis, and interpretation; manuscript preparation and critical revision of the manuscript. CABL: study concept and design; data acquisition, analysis, and interpretation; manuscript preparation and critical revision of the manuscript. RLV: data analysis, interpretation, manuscript preparation, and critical revision of the manuscript. FPN: data analysis, interpretation, manuscript preparation, and critical revision of the manuscript. MC: study and conception, manuscript preparation, and critical revision of the manuscript. ACS: study and conception, manuscript preparation, and critical revision of the manuscript. All authors read and approved the final manuscript.

\section{Acknowledgements}

We would like to thank all of the participants who volunteered their time to participate in the study.

This study was supported by Fundação de Amparo à Pesquisa do Estado de São Paulo (FAPESP-Brazil).

\section{Author details}

'Departamento de Fisiologia, Universidade Federal de São Paulo, São Paulo, Brazil. ${ }^{2}$ Setor de Fisiologia Humana e do Exercício, Faculdade de Educação Física, Universidade Federal de Goiás, Goiânia, Brazil. ${ }^{3}$ Centro de Educação Física e Desporto, Universidade Federal do Espírito Santos, Vitória, Brazil. ${ }^{4}$ Departamento de Ortopedia e Traumatologia, Universidade Federal de São Paulo, São Paulo, Brazil.

Received: 9 July 2013 Accepted: 15 May 2014 Published: 20 May 2014

\section{References}

1. Cascio BM, Culp L, Cosgarea AJ: Return to play after anterior cruciate ligament reconstruction. Clin Sports Med 2004, 3:395-408.

2. Mikkelsen C, Werner S, Eriksson E: Closed kinetic chain alone compared to combined open and closed kinetic chain exercises for quadriceps strengthening after anterior cruciate ligament reconstruction with respect to return to sports: a prospective matched follow-up study. Knne Surg Sports Traumatol Arthrosc 2000, 8:337-342.

3. Beasley WC: Quantitative muscle testing principles and applications to research and clinical services. Arch Phys Med Rehabil 1961, 42:398-425.

4. Frese $\mathrm{E}$, Brown $\mathrm{M}$, Norton B: Clinical reliability of manual muscle testing middle trapezius and gluteus medius muscles. Phys Ther 1987, 67:1072-1076.

5. Aitkens S, Lord J, Bernauer E, Fowler WM Jr, Lieberman JS, Berck P: Relationship of manual muscle testing to objective strength measurements. Muscle Nerve 1989, 12:173-177. 
6. Li RC, Wu Y, Maffulli N, Chan KM, Chan JL: Eccentric and concentric isokinetic knee flexion and extension: a reliability study using the Cybex 6000 dynamometer. Br J Sports Med 1996, 30:156-160.

7. Andrade Mdos S, Fleury AM, de Lira CA, Dubas JP, da Silva AC: Profile of isokinetic eccentric-to-concentric strength ratios of shoulder rotator muscles in elite female team handball players. J Sports Sci 2010, 28:743-749.

8. Fleury AM, Silva AC, de Castro PA, Ejnisman B, Lira CA, Andrade MS: Isokinetic muscle assessment after treatment of pectoralis major muscle rupture using surgical or non-surgical procedures. Clinics (Sao Paulo) 2011, 66:313-320.

9. Shelbourne KD, Nitz P: Accelerated rehabilitation after anterior cruciate ligament reconstruction. J Orthop Sports Ther 1992, 15:256-264.

10. Shelbourne KD, Klootwyk TE, DeCarlo MS: Update on accelerated rehabilitation after anterior cruciate ligament reconstruction. J Orthop Sports Phys Ther 1992, 15:303-308.

11. Pässler HH, Shelbourne KD: Biological, biomechanical and clinical approchaes to the follow-up treatment of ligament surgery in the knee. Sports Exerc Injury 1995, 1:83-95.

12. Astrand P-O, Ekblom B, Messin R, Saltin B, Stenberg J: Intra-arterial blood pressure during exercise with different muscle groups. J Appl Physiol 1965, 20:253-256.

13. Bryant DS, Goss FL, Robertson RJ, Metz KF, Feingold DS: Physiological responses to maximal treadmill and handweighted exercise. Res $Q$ Exerc Sports 1993, 64:300-304.

14. Aminoff T: Prediction of acceptable physical work loads based on responses to prolonged arm and leg exercise. Ergomonics 1998, 41:109-120.

15. Davies CTM, Sargeant AJ: Physiological responses to one- and two- leg exercise breathing air and 45\% oxygen. J Appl Physiol 1974, 36:142-148.

16. Silva AC, Russo AK, Piçarro IC, Schmidt B, Gabbai A, Oliveira AS, Tarasantchi $\mathrm{J}$ : Cardiorespiratory responses to exercise in patients with spinal muscular atrophy and limb-girdle dystrophy. Braz J Med Biol Res 1987, 20:565-568.

17. Noordzij M, Tripepi G, Dekker FW, Zoccali C, Tanck MW, Jager KJ: Sample size calculations: basic principles and common pitfalls. Nephrol Dial Transplant 2010, 25:1388-1393.

18. Barros Neto TL, Russo AK, Silva AC, Piçarro IC, Tarasantchi J, Tálamo E, Freire E: Ventilatory responses to one leg and two legs exercise. Braz J Med Biol Res 1982, 15:223.

19. Jang SH, Kim JG, Ha JK, Wang BG, Yang SJ: Functional performance tests as indicators of returning to sports after anterior cruciate ligament reconstruction. Knee 2014, 21:95-101.

20. Logerstedt D, Grindem H, Lynch A, Eitzen I, Engebretsen L, Risberg MA, Axe MJ, Snyder-Mackler L: Single-legged hop tests as predictors of self-reported knee function after anterior cruciate ligament reconstruction: the Delaware-Oslo ACL cohort study. Am J Sports Med 2012, 40:2348-2356.

21. Kong DH, Yang SJ, Ha JK, Jang SH, Seo JG, Kim JG: Validation of functional performance tests after anterior cruciate ligament reconstruction. Knee Surg Relat Res 2012, 24:40-45.

22. Souissi S, Wong del P, Dellal A, Croisier JL, Ellouze Z, Chamari K: Improving Functional Performance and Muscle Power 4-to-6 Months After Anterior Cruciate Ligament Reconstruction. J Sports Sci Med 2011, 10:655-664.

23. Johnson RJ, Beynnon BD, Nichols CE, Renstrom PA: The treatment of injuries of the anterior cruciate ligament: current concepts review. J Bone Jt Sur 1992, 74:140-151.

24. Noyes FR, Barber SD, Mangine RE: Abnormal lower limb symmetry determined by function hop tests after anterior cruciate ligament rupture. Am J Sports Med 1991, 19:513-518.

25. Andrade MS, Cohen M, Piçarro IC, Silva AC: Knee performance after anterior cruciate ligament reconstruction. Isok Exerc Sci 2002, 10:81-86.

26. Risberg MA, Ekeland A: Assessment of functional tests after anterior cruciate ligament surgery. J Orthop Sports Phys Ther 1994, 19:212-217.

27. Ramonatxo M, Prioux J, Prefault C: Differences in mouth occlusion pressure and breathing pattern between arm and leg incremental exercise. Acta Physiol Scand 1996, 158:333-341.

28. Wasserman K, Whipp BJ, Koyal SN, Beaver WL: Anaerobic threshold and respiratory gas exchange during exercise. J Appl Physiol 1973, 35:236-243.

29. Strauss GR, Bozikovic AJ, Jones GL, Neale GC, Spittles MR, Boyle JJW: Knee extensor strength 12 and 18 weeks post anterior cruciate ligament reconstruction. Isok Exerc Sci 1998, 7:19-26.
30. Laffarge PH, Delalande JL, Maillet M, Vanhecke C, Decoulx J: Reconstruction du ligament croisé antérieur: arthrotomie versus arthroscopie. Rev Chir Orthop 1999, 85:367-373.

31. Roseti L, Buda R, Cavallo C, Desando G, Facchini A, Grigolo B: Ligament repair: a molecular and immunohistological characterization. J Biomed Mater Res A 2008, 84:117-127.

32. Madry H, Kohn D, Cucchiarini M: Direct FGF-2 gene transfer via recombinant adeno-associated virus vectors stimulates cell proliferation, collagen production, and the repair of experimental lesions in the human ACL. Am J Sports Med 2013, 41:194-202.

doi:10.1186/1471-2474-15-163

Cite this article as: Andrade et al:: Assessment of functional impairment after knee anterior cruciate ligament reconstruction using cardiorespiratory parameters: a cross-sectional study. BMC Musculoskeletal Disorders 2014 15:163.

\section{Submit your next manuscript to BioMed Central and take full advantage of:}

- Convenient online submission

- Thorough peer review

- No space constraints or color figure charges

- Immediate publication on acceptance

- Inclusion in PubMed, CAS, Scopus and Google Scholar

- Research which is freely available for redistribution

Submit your manuscript at www.biomedcentral.com/submit
C) Biomed Central 